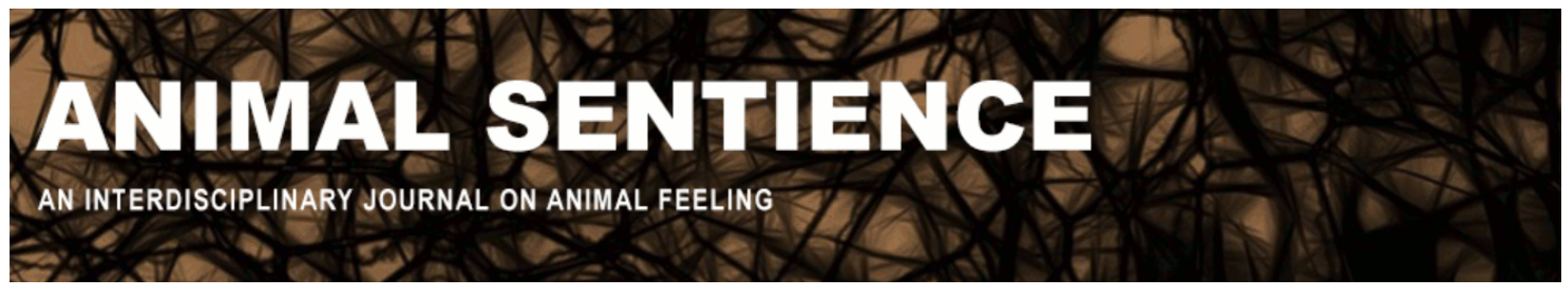

Furlong, Ellen; Silver, Zachary; and Furlong, Jack (2018) Anthropocentrism as cognitive dissonance in animal research?. Animal Sentience 12(11)

DOI: $10.51291 / 2377-7478.1366$

Date of submission: 2018-08-16

Date of acceptance: 2018-09-11

(c) (†)

This article has appeared in the journal Animal

Sentience, a peer-reviewed journal on animal

cognition and feeling. It has been made open access,

free for all, by WellBeing International and deposited

in the WBI Studies Repository. For more information,

please contact

wbisr-info@wellbeingintl.org.

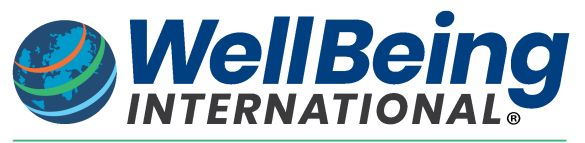

SOLUTIONS FOR PEOPLE, ANIMALS AND ENVIRONMENT 


\title{
Anthropocentrism as cognitive dissonance in animal research?
}

\author{
Commentary on Zentall on Cognitive Dissonance
}

\author{
Ellen Furlong \\ Department of Psychology \\ Illinois Wesleyan University \\ Zachary Silver \\ Department of Psychology \\ Yale University \\ Jack Furlong \\ Department of Philosophy \\ Transylvania University
}

\begin{abstract}
Harmon-Jones et al. (2017) make a thought-provoking suggestion in their commentary on Zentall (2016): Overlooked biases among researchers on animal cognition might lead them to discount the traces of higher-order cognition in animals they study. We find the suggestion both philosophically important and worth further reflection for animal scientists. Harmon-Jones et al. point to two "cognitive dissonance" biases involving the clash between the common human resistance to viewing ourselves as animals/meat-eaters and how these biases might lead to discounting possible advanced cognitive performances in the animals studied. We show how these biases might appear in cognitive research generally and argue for further study on their effects.
\end{abstract}

Ellen Furlong is an assistant professor of psychology and director of the Comparative Cognition Lab at Illinois Wesleyan University. She studies animal cognition (mostly in dogs and nonhuman primates), focusing primarily on decision making. $\underline{\text { Website }}$

Zachary Silver is a graduate student at Yale University where he investigates components of social decision making and social learning in nonhuman animals.

Jack Furlong is emeritus professor of philosophy at Transylvania University. The recipient of several teaching awards, he focused on implications of cognitive science of consciousness during most of his career but in the last two decades narrowed his interests to ethical implications of animal cognitive ethology.
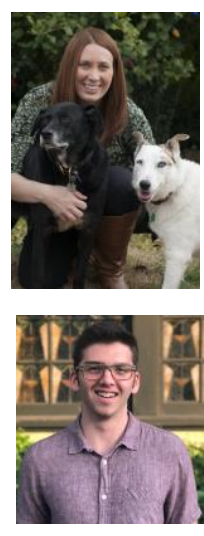

In their commentary on Zentall (2016), Harmon-Jones et al. (2017) suggest the possibility of hidden biases among scientists that would lead them to "downplaying the similarities that we share with nonhuman animals." They note that such biases might be seen as a kind of cognitive dissonance - in this case, a clash between the belief that nonhuman animals display advanced 
cognitive behavior (such as cognitive dissonance) and the belief that such higher order cognition only occurs in humans. In this commentary we will explore the possibility of such hidden biases, taking the possibility seriously and following the pathway a bit further.

Harmon-Jones et al. mention two kinds of beliefs that may, independently or jointly, interfere with good scientific judgment about research on animal cognition. The first kind stems from human resistance to being reminded of our vulnerability and mortality, which may contribute to undue skepticism about animal mentality. The second, from scientific studies of the psychology of meat-eating, shows, "a strong negative relationship between attributed mind and edibility" (Longhnan, Bastian \& Haslam, 2014; Piazza \& Loughnan, 2016).

As to the first source of dissonance, fear of mortality (Becker, 1973), it is certainly possible that scientists are unconsciously influenced by this kind of existential anxiety as they examine how close to human cognition non-humans can come. Some Philosophers (Cavell, 2008) have singled out this shared vulnerability as the moral center of their argument for serious consideration of justice for animals. Regarding this human sense of vulnerability, the work on the "uncanny valley" in artificial intelligence, where a certain amount of "unease" occurs in human subjects toward robots the more they look like humans (Katsyri, Forger, Makarainen \& Takala, 2015), may have some relevance to research on terror management (Hayes et al. 2010). However, as Harmon-Jones et al. (2017) point out, the introduction of "scientific jargon" and consistency with subjects' introductory psychology courses seems to lessen anxiety about facing the fact that humans are animals (Goldenberg, 2001).

The second source of dissonance, edibility, is much closer to concerns about denial of human-like mentality in animals. Loughnan et al. (2010) have examined the mental perturbations caused by what they call the "meat paradox": "people simultaneously dislike hurting animals and like eating meat" (p. 156). One way humans live with this clash of beliefs and desires is to "suppress their moral concern for animals" (p. 156) when they eat meat. Since "people generally believe that animals should be afforded moral consideration because they possess ... mental capacities" (p. 157), this may create cognitive dissonance in scientific research on animal mentality. ${ }^{1}$

This particular form of cognitive dissonance has not gone unnoticed in the history of Western thought. The father of the idea that animals are merely fleshly machines, Rene Descartes, in a moment of candor, admits that one of the sources of resistance to the belief that animals have minds is the fact that humans eat them (Regan, 1989, p. 69; see also Marino, 2017a,b, on chicken cognition).

More conceptual and empirical work is needed on whether cognitive dissonance influences research on animal cognition. Are there vegan skeptics about animal cognition? Or speciesists who are animal cognition enthusiasts? We know of at least one student of dog cognition who describes himself as an "unabashed speciesist" (Berns, 2017, p. 8; cf. Cook et al. 2018).

Longhnan et al. (2014) cite studies suggesting that "People not only judge humanlike [emphasis ours] animals as more pain sensitive but also experience greater autonomic arousal

\footnotetext{
${ }^{1}$ Perhaps participating in the actual pursuit of animal mentality brings out the dissonance that was weakened in the passive, distanced, reception by college students of the scientific findings presented by Goldenberg et al. (2001). Further research is needed to explain how the "meat paradox" might affect the same person differentially, first as first-year college student and then, later in life, as an animal researcher.
} 
when watching them being mistreated" (p. 106). Perhaps the more animal cognition looks like ours, the less likely that we will accept it without anthropodenial. The research on theory of mind shows that resisting the need to distance ourselves from animality yields more accurate scientific judgment. Experimental research on theory of mind in nonhuman animals has at times fallen into the trap of assessing nonhuman animal cognition using human criteria (e.g., Premack \& Woodruff, 1978; see Povinell \& Vonk, 2003, for a similar critique). Some have cited apes' failure on humanoriented false belief tasks as evidence against their having a theory of mind (Call \& Tomasello, 1999; O’Connell \& Dunbar 2003; Kaminski, Call \& Tomasello 2008; Krachun, Carpenter, Call \& Tomasello 2009; Krachun, Carpenter, Call \& Tomasello 2010).

Human theory of mind - and more globally, human cognition - is often viewed as a gold standard to which all other forms of cognition are to be compared. But perhaps our desire to understand non-human theory of mind (or simply non-human social cognition) in human terms obscures the "alien" nature of animal cognition. False beliefs may be less relevant in non-human social cognition (Andrews, 2005; Call \& Tomasello, 2008; Martin \& Santos, 2016; Povinelli \& Vonk 2003).

A different perspective on this question can be seen in comparative work on memory. Many species of birds perform feats of memory ${ }^{2}$ that dwarf human memory capacity. For example, Clark's nutcrackers live in the highest elevation of the San Francisco Peaks, a habitat with harsh winter conditions and food shortages (Balda \& Kamil, 2006). Throughout autumn, Clark's nutcrackers may cache up to 33,000 seeds in 7,000 unique cache sites (Vander Wall \& Balda, 1977); 80\% of searches result in recovered caches (Tomback, 1980; Turek \& Kelso, 1968). These birds accomplish this even though they spend fewer than 30 seconds caching at each site and may not return to the cache site for many months. This capacity is even more impressive considering that the birds must remember the locations despite sometimes drastic changes to the substrate and even possible elimination of landmarks: they cache in greenery and retrieve in snow. This allows them to survive harsh winters and even to breed earlier in the spring so their offspring face less competition and have time to grow larger and stronger by the time the next winter comes around (Balda \& Kamil, 2006). It would clearly be pointless, ethologically, to try to assess the cognitive virtuosity of Clark's nutcrackers in terms of human kinds of memory skills.

Although the commentary of Harmon-Jones et al. that sparked this modest elaboration might seem a small point in the research on animal cognitive dissonance, it reminds us that our anthropocentric tendency to relativize nonhuman cognition to human cognition is a cognitive bias that can distort human judgment as surely as other human cognitive biases can (Fischoff, 1982; Kahneman, 2003; Larrick, 2004; Nisbett, Krantz, Jepson \& Kunda, 1983; Stanovich, 1999).

\footnotetext{
${ }^{2}$ The authors would like to thank corvid scientist Professor Rebecca Fox of Transylvania University for insightful discussions and helpful references.
} 


\section{References}

Andrews, K. (2005) Chimpanzee theory of mind: Looking in all the wrong places? Mind \& Language 20(5), 521-536

Balda, R. P. and Kamil, A. (2006) Linking life zones, life history traits, ecology, and spatial cognition in four allopatric southwestern seed caching corvids. Papers in Behavior and Biological Sciences 36

Becker, E. (1973) The Denial of Death. New York: Simon and Schuster

Berns, G. (2017) What It's Like to Be a Dog: And Other Adventures in Animal Neuroscience. New York: Basic Books

Call, J. and Tomasello, M. (1999) A nonverbal false belief task: The performance of children and great apes. Child Development 70(2), 381-395

Call, J. and Tomasello, M. (2008) Does the chimpanzee have a theory of mind: 30 years later. Trends in Cognitive Development 12(5), 187-192

Cavell, S., Diamond, C., McDowell, J., Hacking, I., \& Wolfe, C. (2008) Philosophy and Animal Life. New York: Columbia University Press

Cook, P., Prichard, A., Spivak, M. and Berns, G. S. (2018) Jealousy in dogs? Evidence from brain imaging. Animal Sentience 22(1)

Fischoff, B. (1982). For those condemned to study the past: Heuristics and biases in hindsight. New Directions for Methodology of Social and Behavioral Science, 4, 79-93

Goldenberg, J. L., Pyszczynski, T., Greenberg, J., Solomon, S., Kluck, B. and Cornwell, R. (2001) I am not an animal: Mortality, salience, disgust, and the denial of human creatureliness. Journal of Experimental Psychology: General, 130(3), 423-435

Harmon-Jones, C., Haslam, N. and Bastian, B. (2017) Dissonance reduction in nonhuman animals: Implications for cognitive dissonance theory. Animal Sentience 12(4)

Hayes, J., Schimel, J., Arndt, J. and Faucher, E. H. (2010) A theoretical and empirical review of the death-thought accessibility concept in terror management research. Psychological Bulletin 136(5), 699-739.

Kahneman, D. (2003) A perspective on judgment and choice. American Psychologist 58, 697-720.

Kaminski, J., Call, J. and Tomasello, M. (2008) Chimpanzees know what others know, but not what they believe. Cognition 109(2), 224-234

Katsyri, J., Forger, K., Makarainen, M. and Takala, T. (2015) A review of empirical evidence on different uncanny valley hypotheses: Support for perceptual mismatch as one road to the valley of eeriness. Frontiers in Psychology 10

Krachun, C., Call, J. and Tomasello, M. (2010). A new change-of-contents false belief test: Children and chimpanzees compared. International Journal of Comparative Psychology 23(2).

Krachun, C., Carpenter, M., Call, J. and Tomasello, M. (2009). A competitive nonverbal false belief task for children and apes. Developmental Science 12(4), 521-535

Larrick, R. P. (2004). Debiasing. In Koehler, D. J. \& Harvey, N. (Eds.), Blackwell Handbook of Judgment and Decision Making. Blackwell Publishing Ltd.

Loughnan, S., Bastian, B. and Haslam, N. (2014) The psychology of eating animals. Current Directions in Psychological Science 23(2), 104-108 
Loughnan, S., Haslam, N. and Bastian, B. (2010) The role of meat consumption in the denial of moral status and mind to meat animals. Appetite 55, 156-159

Marino, L. (2017a) Thinking chickens: A review of cognition, emotion, and behavior in the domestic chicken. Animal Cognition 20(2), 17-147

Marino, L. (2017b) The inconvenient truth about thinking chickens. Animal Sentience 17(1)

Martin, A. and Santos, L. R. (2016) What cognitive representations support primate theory of mind? Trends in Cognitive Sciences 20(5), 375-382

Nisbett, R. E., Krantz, D. H., Jepson, C. and Kunda, Z. (1983) The use of statistical heuristics in everyday inductive reasoning. Psychological Review 90, 339-363

O'Connell, S. and Dunbar, R. I. M. (2003) A test for comprehension of false belief in chimpanzees. Evolution and Cognition 9(2), 131-140

Piazza, J. and Loughnan, S. (2016) When meat gets personal, animals' minds matter less. Social Psychological and Personality Science 7(8), 867-874

Povinelli, Daniel J. and Vonk, J. (2003). Chimpanzee minds: Suspiciously human? Trends in Cognitive Sciences 7(4), 157-160

Premack, D. and Woodruff, G. (1978) Does the chimpanzee have a theory of mind? Behavioral and Brain Sciences 1(4), 515-526

Regan, T. (1989). Animal Rights and Human Obligations: An Anthology (co-editor with Peter Singer) N.J.: Prentice-Hall, 2nd edition

Stanovich, K. E. (1999) Who is rational? Studies of individual differences in reasoning. Mahwah, NJ: Erlbaum

Tomback, D. F. (1980) How nutcrackers find their seed stores. Condor 82, 10-19

Turcek, F. J. and Kelso, L. (1968) Ecological aspects of food transportation and storage in the Corvidae. Communications in Behavioral Biology A(1), 277-297

Vander Wall, S. B. and Balda, R. P. (1977) Coadaptations of the Clark's nutcracker and the pinon pine for efficient seed harvest and dispersal. Ecological Monographs 47(1), 89-111

Zentall, T. R. (2016) Cognitive dissonance or contrast? Animal Sentience 12(1) 